\title{
EDITORIAL
}

\section{OCCUPATIONAL HEALTH AND DISEASE PREVENTION IN THE CZECH REPUBLIC: HISTORY AND PRESENT SITUATION}

\author{
Milan Tuček ${ }^{1,2}$ \\ ${ }^{1}$ Institute of Hygiene and Epidemiology, First Faculty of Medicine, Charles University, Prague, Czech Republic \\ ${ }^{2}$ Czech Society of Occupational Medicine, Czech Medical Society of J. E. Purkyně, Prague, Czech Republic
}

Address for correspondence: M. Tuček, Institute of Hygiene and Epidemiology, First Faculty of Medicine, Charles University, Studničkova 7 , 12800 Prague 2, Czech Republic. E-mail: milan.tucek@lf1.cuni.cz

https://doi.org/10.21101/cejph.a6164

Modern occupational health $(\mathrm{OH})$ is a multidisciplinary expert area, which consists of several knowledge domains including

- occupational medicine (medical discipline focusing on occupational diseases, their diagnostics, treatment and prevention);

- occupational health services (protection of workers against hazards at work, protection of their health and promotion of health and work ability);

- occupational psychology (identification, assessment and prevention of psychological and psycho-social factors at work and their prevention and control);

- occupational hygiene (measurement of physical, chemical, biological and other hazardous agents at the workplace, risk assessment and advice in preventive actions);

- ergonomics (identification, assessment and prevention of unphysiological working conditions, such as repetitive movements, their prevention and control);

- occupational safety including accident prevention and development of safe work environments and working practices.

As defined by the World Health Organization (WHO) (1) and International Labour Organization (ILO) occupational health aims at:

- the promotion and maintenance of the highest degree of physical, mental and social well-being of workers in all occupations;

- the prevention amongst workers of departures from health caused by their working conditions;

- the protection of workers in their employment from risks resulting from factors adverse to health;

- the placing and maintenance of the worker in an occupational environment adapted to his or her psychological capabilities and;

- the adaptation of work to the worker and of each worker to his or her job.

Occupational medicine (OM) is one of the major disciplines of occupational health. While occupational medicine is a speciality of physicians, occupational health covers a broader spectrum of different health protective and promotional services. Occupational health services (OHSs), provided in the Czech Republic as a complex of preventive medical examinations, workplace inspections, consultations, and recommendations by medical staff, i.e. by physicians and nurses, are officially named by Czech law Occupational Medical Services (OMSs). Other part of occupational health services is represented by safety at work experts, psychologists, ergonomists, and toxicologists. Occupational hygiene is historically the integral part of hygiene and occupational medicine (both are perceived as medical disciplines), but provided still more by nonmedical experts with necessary special training. Occupational medicine studies the impact of work and working conditions on the health of workers. It deals with the prevention, diagnostics, treatment, and medicolegal aspects of diseases caused or exacerbated by working conditions. This specialization comprehensively deals with relations between work and health. It prescribes procedures for building a safe and healthy working environment and handles the problem of adapting the work to the abilities of workers with regard to their physical and mental health, it is concerned about health promotion in workers, including evaluation and promotion of their working capacity, and studies the impact of work and working conditions on the occurrence of chronic noninfectious diseases, the progression of which may be significantly influenced by work and working conditions. The information obtained by studying the level of exposure to adverse factors in working settings and their impact on the health and well-being of workers is used for setting regulatory measures aimed at ensuring health protection at work, optimization of working conditions and preservation of working capacity.

\section{Historical Overview}

The first Injury Insurance Act in the territory of former AustroHungarian Empire was adopted in 1887. The National Assembly of the Czechoslovak Republic ratified ILO's Occupational Diseases Indemnity Convention in 1932, and on June 1, 1932 was issued Act No. 99/1932 Coll. about indemnity of occupational diseases. Prof. František Procházka, working at the Medical Faculty of Charles University in Prague, paid attention to occupational hygiene and occupational diseases and wrote the first textbook named Occupational Hygiene in 1929, in which he described the nature of business with its health risks in a timeless manner and emphasized the importance of preventive counselling in order to minimize health damage arising in association with work - the principles adopted after decades in the philosophy of safety and health at work by the European Union. The first Out-Patient Department for Occupational Medicine in the former Czechoslovakia was established at the Charles University in Prague 
in 1932 under the leadership of Prof. Jaroslav Teisinger. The system of occupational health services in Czechoslovakia before 1989 might have served as a model worth following in several aspects, e.g. as regards resources and staffing. Research in the field of occupational health was on a very high level, and the hygienic limits set for the working environment were relatively strict in comparison with many European countries. In practice, however, the system did not always work as expected (2). Twelve institutes of occupational medicine were established by the Ministry of Health in 1945, the Czech Society of Occupational Medicine in 1946 and the first In-Patient Department of Occupational Diseases in 1947 (Prague). The First Congress of Occupational Diseases was held in Prague in 1942 (the last 24th Congress of Occupational Medicine in September 2019 in Mariánské Lázně*). The first issue of Journal of Occupational Medicine was published in 1949. The Institute of Occupational Hygiene and Occupational Diseases was established in Prague in 1952 (now special centre of the National Institute of Public Health); regional institutes of occupational medicine were abolished and transformed to two parts - one part was moved to the public health inspection (occupational hygiene), another part to hospitals (occupational diseases). During the communist era (1948-1989) was frequently banned to disclose information about workplace hazards and risk management. The gap between political proclamations and reality was on the increase. Unfortunately, after the "velvet" revolution in 1989, some good practices and knowledge bases in OHS have been abandoned and almost completely destroyed. For example, existing factory/company doctors familiar with specific working conditions and having the appropriate knowledge of the health of individual workers could provide both preventive and curative care: since 1 January 1992 factory preventive care has been transformed to occupational medical service where curative care is not possible. During the 1990s, dramatic changes in the economic system had deep impact on work life. Currently, the differences between the Czech Republic and the EU countries concerning the structure of the labour market are relatively small. The introduction of new technologies, changes in the demographic structure, as well as in social and cultural life influenced the conditions of work and living of workers. Unfortunately, the social dimension of these processes has been often underestimated (3). The restructuring of OHSs after the revolution in 1989 resulted in the reduction of the number of physicians and nurses engaged in those services. Occupational nurse specialization was possible according to the Act No. 96/2004 Coll. Occupational medicine conception was accepted by the Ministry of Health on 7 April 2004, and former specialization named occupational hygiene and occupational diseases was transformed by Act No. 95/2004 Coll. to the basic specialization of physicians named occupational medicine in duration of 4 years, but at present after repeated law changes occupational medicine is postgraduate discipline after basic specialization in general medicine, internal medicine and hygiene and epidemiology.

\section{Legislative Framework}

Former Czechoslovakia ratified the ILO's Occupational Health Services Convention (No. 161/1985) in 1988, and Occupational Safety and Health Convention (No. 155/1981) in 1989. During the process of accession to the EU, the Czech Republic has transposed

\footnotetext{
* https://www.pracovni-lekarstvi.cz
}

into the national legislation all EU directives in the field of occupational health and safety, particularly the fundamental Framework Directive 89/391/EEC, on the introduction of measures to encourage improvements in the safety and health of workers at work. Former framework legislation at the national level (Act No. 20/1966 Coll., on national health care, Decree of the Ministry of Health No. 49/1967 on the health fitness assessment to work) has been replaced by Public Health Protection Act No. 258/2000 Coll., and later after national health reform valid since 1 April 2012 by Act No. 373/2011 Coll., on specific health services, where are special paragraphs 53-60 about occupational medical services.

\section{Occupational Medical Services}

Occupational medical services are defined as preventive services, which include the impact assessment of work, working environment and working conditions on health, workplace inspections and preventive medical fitness assessment for work aimed at protecting the health and protection against occupational accidents, occupational diseases and work-related diseases, training in first aid and regular surveillance in the workplace. Providers of occupational medical services are general practitioners (GPs) and occupational health specialists (certified occupational physicians). Written contract for the provision of occupational health services must be concluded with the employer. In the risk category 1 only (where no specific conditions are set by other legislation, see details below) may be provided preventive medical check-ups by GP who has client in his/ her general health insurance register (registering GP). Other OHSs must be contracted by other OHSs provider (written statement). Recognition of occupational diseases is allowed to the providers of occupational medicine who have obtained authorization from the Ministry of Health.

\section{Role of Physicians in OMSs}

One of the crucial medicolegal activity of OMS providers is the certification of medical fitness for work issued by examining physician (in the Czech Republic occupational physician or general practitioner) and based on knowledge of working conditions/health risks at work and on results of occupational medical examinations of workers/employees.

Working conditions are generally assessed by specific health risk assessment, e.g. system of categorization of work operations established in the Czech Republic on monitoring 13 harmful factors in the workplace (dusts, chemical substances, noise, vibrations, electromagnetic fields, physical load, working position, thermal exposure, cold exposure, psychical burden, visual burden, biological agents, high air pressure); exposure to ionizing radiation is assessed separately. Special guidelines for assessment of various types of risks are available. The category of the work operation and the most important risk factor determine the range of medical examination (e.g. basic clinical examination only or special examination like spirometry), frequency of periodic medical examination of workers (between 1 and 6 years) and frequency of periodic measurements of different harmful factors at workplaces. There are 4 risk categories of work operations according to the extent of risk: category 1 is the safest, category 4 is the worst. Some occupations (drivers, railway 
workers, firemen, etc.) have besides the examinations described above special content of preventive occupational medical examinations more or less derived from international recommendations (4). Occupational medical examinations of individuals (workers and employees) are initial/entry, periodic, extraordinary, output, and consequential.

Medical fitness assessment for work represents the determination of whether an individual is fit to perform his or her tasks without risk to self or others. Detailed knowledge of both working and health conditions is required. Because of the changing nature of these two variables, fitness for work is a dynamic concept. Its assessment may be required at the beginning of the work relationship, after transfer of positions within employment, after the emergence of a health problem, or periodically, especially for hazardous, physically demanding or safety sensitive jobs. The certification of medical fitness for work issued by examining physician is one of the crucial medicolegal activity of OMS providers. A keystone of quality performance by a physician is the familiarity with specific working conditions and demands of the respective job and the knowledge of the state of health of individual workers $(5,6)$. The certificate of medical fitness for work does not contain sensitive medical data (diagnosis). On the other side there must be clearly expressed that the assessed person is medically fit for the job or medically fit for the job with the certain condition/medical restriction or medically unfit (sometimes permanently) for the job. There are different written or electronic forms for certification of medical fitness for work that should be unified and standardized for practical needs of OMS providers and employers. The introduction of the standard of employer's request and certificate of medical fitness for work is recommended for the current practice, the correct use of this standard would largely eliminate risk of the annulment of certificate for formal mistakes in appeal procedure $(7,8)$. Correct medical fitness assessment for work is crucial from medical point of view for prevention of negative health impact. Conclusions of certificates of medical fitness assessments for work were usually medically fit, but sometimes with certain condition/ medical restriction, which is related to the concrete technology, type of production or service and individual health status (mainly allergy in medical history, impaired vision, sometimes impaired hearing, metabolic, cardiovascular, or neurological diseases). The medical unfitness for work is relatively rare. The simplified approach, when only health examinations of workers without any other important activities (such as workplace visits, risk assessment, consultations for employers and employees etc.) are realized, may have serious consequences, particularly in incorrect medical fitness assessment for work especially for vulnerable workers (e.g., pregnant women, older workers), which can lead to the negative impact on occupational health and can influence the general perception of working culture in enterprises.

Association between work risk category and occupational disease (OD) was expressed as probability of expected OD incidence in different risk categories (1-4) based on monitoring of 13 harmful factors in the workplace. In category 1 (1.8 thousand workers under minimal health risk) was expected probability of OD $5.10^{-5}$, in category 2(1.7 thousand workers under acceptable level of health risk) was expected probability of OD $2.10^{-4}$, in category 3 (476 thousand workers under considerable level of health risk where the level of factor load exceeded given exposure limits) was expected probability of OD $2.10^{-3}$ and in category 4 (14 thousand workers under high level of health risk) was expected probability of OD $7.10^{-3}(9)$.

\section{Conclusions}

The Occupational Safety and Health Framework Directive 89/391 EEC marked some fundamental improvements in occupational safety and health, specifying minimum obligations as regards health and safety throughout the European Union. Globalization, demographic shifts, migration and new technologies have produced far-reaching changes in the world of work and new challenges for the health and safety of workers. The main focus of occupational health is possible to express in three different objectives: the maintenance and promotion of workers' health and working capacity, improvement of working environment and work to become conducive to safety and health, and development of work organizations and working cultures in a direction which supports health and safety at work and in doing so also promotes a positive social climate and smooth operation and may enhance productivity in the undertakings. Modern occupational health covers a broad spectrum of different health protective and promotional services and occupational medicine as a speciality of physicians dealing with the prevention, diagnostics, treatment, and medicolegal aspects of diseases caused or exacerbated by working conditions is still one of the major disciplines of occupational health. Although there is limited number of occupational physicians, they still have an essential and important role in the tracing and medical assessment of work-related and occupational diseases and cannot be easily replaced by other medical specialists. Unfortunately, the current social situation does not indicate the necessary support for occupational medicine and there is a real risk of the extinction of this specialization.

\section{Acknowledgement}

The work was supported by the programme PROGRES Q25/LF1, Charles University, Prague.

\section{RERERENCES}

1. Westerholm P, Baranski B, editors. Guidelines on quality management in multidisciplinary occupational health services. Bilthoven: WHO European Center for Environment and Health; 1999.

2. Cikrt M, Pelclová D, Markvart K, Lukáš E, Kř́íz J. Occupational and environmental medicine in Czech Republic. Int Arch Occup Environ Health. 1997;69(2):79-82.

3. Organizational models and functions of occupational health services in countries in socioeconomic transition: present state and perspectives. Summary report on a WHO meeting, Lodz, Poland, 15-17 December 1994. Int J Occup Med Environ Health. 1996;9(3):197-200.

4. UIMC Railway medical guidelines. Guidelines for medical fitness of railway personnel in safety critical functions. Paris: International Union of Railways; 2019.

5. Leino T, et al. Comparative analysis of occupational health system and practices as part of preventive health care systems in seven European countries. Part 1 Document based analysis. European Commission INCO - Copernicus program report of the project no. PL 973108. Helsinki: Finnish Institute of Occupational Health; 1999.

6. Tuček M. Occupational medical services as a part of health reform. $\mathrm{Zdr}$ Forum. 2012;2012(7):18-20. (In Czech.)

7. Tuček M. The Medicolegal certification of medical fitness for work: necessity of standardization of the certificate. Eur J Biomed Inform. 2013;9(1):7-10.

8. Tuček M. Introduction to occupational health. In: Bencko V, et al. Hygiene and epidemiology: selected chapters. 2nd ed. Prague: Karolinum Press; 2019. p. 111-24.

9. Šubrt B, Tuček M. Occupational medical services. 4th ed. Olomouc: ANAG; 2019. 